\title{
Timing of Seasonal Sales
}

\section{Pascal Courty; Hao Li}

The Journal of Business, Vol. 72, No. 4. (Oct., 1999), pp. 545-572.

Stable URL:

http://links.jstor.org/sici?sici=0021-9398\%28199910\%2972\%3A4\%3C545\%3ATOSS\%3E2.0.CO\%3B2-2

The Journal of Business is currently published by The University of Chicago Press.

Your use of the JSTOR archive indicates your acceptance of JSTOR's Terms and Conditions of Use, available at

http://www.jstor.org/about/terms.html. JSTOR's Terms and Conditions of Use provides, in part, that unless you have obtained prior permission, you may not download an entire issue of a journal or multiple copies of articles, and you may use content in the JSTOR archive only for your personal, non-commercial use.

Please contact the publisher regarding any further use of this work. Publisher contact information may be obtained at http://www.jstor.org/journals/ucpress.html.

Each copy of any part of a JSTOR transmission must contain the same copyright notice that appears on the screen or printed page of such transmission.

JSTOR is an independent not-for-profit organization dedicated to and preserving a digital archive of scholarly journals. For more information regarding JSTOR, please contact support@jstor.org. 


\section{Timing of Seasonal Sales*}

\section{Introduction}

A common phenomenon in retail pricing is sales. In recent years, sales have become an important pricing strategy for seasonal goods (Pashigian 1988). An additional observation is that sales have started earlier in the season in recent years. Whereas New Year's Day traditionally marked the beginning of sales in the winter season, sales have recently advanced to before Christmas and even around Thanksgiving. For example, Pashigian and Bowen (1991) cite a report by the National Retail Merchants Association on the monthly distribution of yearly markdowns showing that, for apparel, the market share of total annual markdowns taken in June (in the springsummer season) and December (in the fall-winter season) has been increasing since the 1970s. Pashigian and Bowen's own empirical work also shows that, when average monthly prices of women's apparel are compared across time, December prices have decreased relative to the average season price. What explains the trend toward

* We are grateful for the comments made by Peter Pashigian, Steve Salant, the editor, an anonymous referee, and seminar participants at Universitat Pompeu Fabra and Hong Kong University of Science and Technology. Courty's work was supported by grant DGES PB96-0302 from the Spanish Ministry of Education and by grant 1997 SGR 00138 from the Generalitat de Catalunya. Li's work was supported by a grant from the Research Grants Council of the Hong Kong Special Administrative Region, China, Project no. HKU7148/98H.

(Journal of Business, 1999, vol. 72, no. 4)

() 1999 by The University of Chicago. All rights reserved. 0021-9398/1999/7204-0005\$02.50
We present a model of timing of seasonal sales in which stores choose several designs before the season without knowing which, if any, is fashionable. Stores begin by charging high prices to capture the fashion market. As the season approaches the end with goods still unsold, stores have sales to capture the discount market. More designs and greater price competition in the discount market induce earlier sales. The results are consistent with the observation that the trend toward earlier sales since the mid-1970s coincides with increasing product varieties in fashion goods markets and increasing store competition. 
early sales in the clothing industry? Should one expect a similar trend in markets for other seasonal goods?

Around the same time that sales began to start earlier in the season, the number of varieties offered became more important. In clothing markets, for example, in addition to traditional formal and tailor-made suits and dresses, there has been an increase in sportswear, which gives producers more latitude to mix different colors and fabrics and create new styles. The market share of sportswear in women's apparel increased from around $42 \%$ in 1967, to $56 \%$ in $1972,69 \%$ in 1977, and $78 \%$ in 1982 (Pashigian 1988). Do increasing product varieties play a role in the trend toward early sales in markets for seasonal goods?

Existing models of sales (Varian 1980; Salop and Stiglitz 1982; Lazear 1986; Pashigian 1988) explain why a store may use sales to maximize profits in the presence of demand uncertainty. Absent from the literature is an analysis of the timing of sales in a competitive context. ${ }^{1}$ Timing of sales is an important strategic issue for seasonal goods markets because stores face a deadline to sell the capacity they ordered at the beginning of the season, and they suffer great losses when they are forced to carry their goods to the next season.

We extend Lazear's model of sales to account for timing of sales, product variety, and store competition explicitly. We begin with the model of a single store that orders one design of its product at the beginning of the season without knowing if it will be fashionable or not, that is, whether it will command a market of fashionable consumers or discount buyers. While fashionable consumers are impulsive buyers who may or may not buy at a list price, both fashionable consumers and discount buyers buy at a lower discount price. In deciding when to start sales, the store faces a trade-off between selling the goods early in the season and selling them cheap at the discount price. Sales occur earlier if there are fewer fashionable consumers in the market as in recessions, if the store learns faster about the market as when it attracts more frequent customer visits, if the store faces a greater cost of delaying sales as when it has a premium location with high rent, or if the fashion premium decreases as when product labeling and bar coding reduce the cost of price adjustments and increase the net sales profits. Sales do not necessarily occur earlier in stores with more competent sales forces: these stores learn faster about consumer demand, which tends to induce early sales, but at the same time they are more likely to sell their goods at the list price, which tends to delay sales.

1. Exceptions include Feng and Gallego (1995) and Krider and Weinberg (1998) in the marketing literature. Their models do not have the learning feature that is the driving force in our model. Sobel (1984) studies the timing of periodic sales in a market for durable goods in which a new cohort of consumers enters in each period. The demand structure in his model is similar to ours. 
Stores often order multiple designs of a product at the beginning of the season. For example, a brand name of shirts carries slightly differentiated designs with different colors, fabrics, or styles. There is little substitution among the designs for fashionable consumers, but for discount buyers the designs can be perfect substitutes. In our model, the monopoly store has incentives to order several designs without knowing which one, if any, will be fashionable, even if doing so does not increase the fashion premium or the size of the fashion market. The marginal benefit of an additional variety comes from the reduction of the risk in putting a "hot" design on sale, and, as a result, having a greater number of designs induces the store to put one of them on sale earlier to test the market. Thus, our model of monopoly store implies a relation between increasing product varieties and earlier sales. When the cost of creating designs decreases, our model predicts both increasing product varieties and earlier sales.

Increasing product varieties in recent years in many markets have also intensified competition among retail shops. Standard models of sales based on monopoly pricing cannot account for the effects of increasing competition. ${ }^{2}$ Indeed, by applying his monopoly sales model, Lazear (1986) reasons that since store competition reduces customer traffic at each store and hence the pace of learning about the demand, stores "will select lower initial prices and lower those prices more slowly." This conclusion seems to contradict the above-mentioned coincidence of the trend toward earlier sales and increasing product varieties in the apparel market. The inadequacy of Lazear's prediction is due to the fact that he did not take into account the role of price competition.

Our model allows us to examine the relation between increasing competition in retail businesses and the timing of sales. At the beginning of the season, several stores each choose a design and do not know which one of the designs, if any, will be fashionable. As in the case of the monopoly store, the market consists either of fashionable consumers who are willing to pay the list price for the fashionable design only or of discount buyers who are willing to pay at most the discount price and who buy from the store with the lowest price. This structure of consumer demand captures the intuition that price competition is not as important in fashion markets as it is in the discount market.

The main result here is that sales occur earlier under competition. Stores advance the date of sales in an attempt to capture the discount

2. Pashigian (1988) presents a model of competition in the sense of free entry into the retailing business, but he assumes that stores can commit to intertemporal price schedules. This does not seem to capture the nature of price competition in retail business. We will consider both the Pashigian type of ex ante competition by way of product variety and, more important, ex post price competition among stores without assuming that they can commit to intertemporal price schedules. 
market before their competitors. There is a negative externality among the stores in the sense that they would be better off if they could coordinate to delay sales. Competition reduces the stores' revenue at any moment in time and therefore reduces the gains from delaying sales. Experimenting with the list price becomes more costly under increasing competition. Our finding is consistent with the consensus of retail industry officials that increasing store competition has played an important role in the unraveling of the sale date in recent seasons. ${ }^{3}$

Price competition for discount buyers implies that sales prices can be quite variable. A monopoly store chooses the sales price to be the reservation price of discount buyers. Under price competition in the discount market, stores must vary their sales prices randomly in order not to lose out in the competition. Although sales prices are random, expected discounts increase as the season approaches the end. This is consistent with the observation that discounts are greater when sales occur later (Pashigian 1988). As in the case of monopoly, an increase in the service quality of stores has ambiguous effects on the timing of sales because it increases the benefits from experimenting with the list price while speeding up the learning process. However, while the effect of increases in the service quality on the speed of learning does not depend on the number of stores, the benefits from experimenting with the list price decrease as store competition increases. Thus, more competitive markets are more likely to exhibit a relation between earlier sales and better services.

Product varieties in a market are closely related with the degree of store competition. If a store can order a new design at some cost to compete against existing designs, then new varieties will be created until the expected revenue from sharing the fashion market equals the cost of ordering a new design. The expected revenue from one share of the fashion market does not depend on the discount price because competitive stores extract no surplus from the discount buyers. In contrast, the marginal benefit to a monopoly store of acquiring an additional design arises from the reduction in the risk of putting the fashionable design on sale. The marginal benefit depends negatively on the willingness to pay by discount buyers because the monopoly store extracts all their surplus. It follows that the equilibrium number of varieties under competition is greater than the number of varieties that a monopoly store will order.

Existing models of sales can explain some well-documented withinseason and across-season regularities in seasonal goods markets. Lazear (1986) explains why prices fall as the season proceeds. Pashigian

3. Pashigian (1988, n. 1) acknowledges this consensus as the officials' explanation of some recent trends in seasonal price behavior, although his own explanation focuses instead on increasing importance of fashion to consumers. 
(1988) and Pashigian and Bowen (1991) argue that greater demand uncertainty in the market for women's apparel explains why percentage markups and markdowns are greater for women's apparel than for men's apparel. Pashigian, Bowen, and Gould (1995) note that seasonal variation in retail prices has increased in the apparel market but decreased in the automobile market, and they suggest that the reason lies in the decreasing cost of innovation for apparel and increasing cost for cars. By explicitly considering product variety and price competition, our model complements the existing models of sales and explains also across-season changes in the timing dimension of store sales strategies. In clothing markets, new production technologies that reduced the cost of innovations have made it easier both for existing stores to order more designs and new entrants to establish their market share, prompting earlier sales in the season. In contrast, increasing international competition and increasing cost of innovation in the automobile market have opposite effects on the timing of sales, which may explain why seasonal price data in the automobile market do not exhibit the same pattern of earlier sales as in apparel markets.

This article is organized as follows. In the next section, we present a stylized model of timing of seasonal sales. Section III uses the model to study the determinants of timing of sales for a monopoly store, and Section V studies competitive timing of sales. After deriving the main analytical results in there sections, we present their respective empirical implications in Sections IV and VI. In Section VII, we discuss how to relax the assumption of store and product symmetry and extend the model to address issues such as differentiated learning pace and product turnover rate. Section VIII concludes with a brief summary and some remarks on regulation policies. Proofs of the propositions can be found in the appendix.

\section{A Model of Seasonal Sales}

The season begins with $k \geq 1$ designs of a product in the market and lasts for $N$ selling periods. Stores cannot order new designs during the season because of high ordering cost. Let $\beta$ be the store's discount factor between two adjacent selling periods. The small discount factor can be interpreted as a high opportunity cost of keeping the designs on the shelf. For simplicity, we assume throughout this article that, at the end of the $N$ th period, the store has zero salvage value for unsold designs. This assumption can be easily relaxed without changing the basic results of the model.

We assume that the market is homogeneous with a fixed size normalized to one. The market consists either of fashionable consumers attracted to one of the designs or of discount buyers who do not care about fashion. Fashion buyers are willing to pay $v_{\mathrm{H}}$ for the design they 
like and zero for any other design while discount buyers are willing to pay $v_{\mathrm{L}}<v_{\mathrm{H}}$ for any design. ${ }^{-4}$ We refer to $v_{\mathrm{H}}$ the "list price," $v_{\mathrm{L}}$ the "discount price," and the difference "fashion premium." At the beginning of the season, stores do not know which one of the designs, if any, is fashionable. They believe that each design is fashionable with probability $\pi / k$ and no design is fashionable with probability $1-\pi$. Stretching the interpretation of this prior belief a bit, we say that stores estimate that the fashion market is of size $\pi$.

Since there are only two possible consumer valuations, timing of sales can be given a definite meaning. If consumers buy a design when the price is below or equal to their valuation, no store will charge a price between the maximum discount price $v_{\mathrm{L}}$ and the list price $v_{\mathrm{H}}$. Whenever a store charges a discount price (a price below $v_{\mathrm{L}}$ ), we say that the store has "sales." Stores have no incentive to continuously decrease prices. ${ }^{5}$

Throughout this article, we maintain the assumption that consumers do not behave strategically. This assumption is commonly made in models of sales (Varian 1980; Lazear 1986; Pashigian 1988). ${ }^{6}$ Justifications for the assumption include a limited supply of fashion goods, high search cost, quick fashion turnover, and a short selling season. These conditions are likely to be satisfied in markets for high-end fashion clothes and accessories, Christmas cards, calendars, and souvenirs for events such as NBA playoffs.

In each period, consumers visit all stores and decide whether or not to purchase the designs at the prices posted. In this simple setting, stores offer the designs at the list price $v_{\mathrm{H}}$ in the first period if there is a good chance of selling one of them. If consumers do not buy any of the designs at the list price, stores learn immediately that the designs are not fashionable and will charge discount prices (have sales). In reality, stores are likely to learn more slowly. We model this by assuming that fashionable consumers are impulse buyers who buy the design they like only when they are in a buying mood, which occurs with probability $q<1$. For simplicity, we assume that fashionable buyers buy the design they like with probability $q$ for any price between $v_{\mathrm{L}}$ and $v_{\mathrm{H}}$ and probability one if the price is $v_{\mathrm{L}}$ or lower. Discount buyers buy the cheapest design if the price does not exceed $v_{\mathrm{L}}$. If several designs are

4. Alternatively, there is a single consumer who either likes one of the designs and is willing to pay $v_{\mathrm{H}}$ or does not like the designs and is willing to pay only $v_{\mathrm{L}}$ for any design.

5. Although stores have many opportunities to adjust their prices, sales typically occur very infrequently during a season (Gallego and van Ryzin 1994).

6. Consumer strategic behavior is considered in a theoretical literature (e.g., Stokey 1981; Fudenberg and Tirole 1983; Gul, Sonnenschein, and Wilson 1986), initiated by Coase's (1972) analysis of durable goods monopoly. Much of the literature is concerned with price behavior in the limit case (the Coase conjecture) and, with the exception of Gul (1987), does not consider price competition by sellers. 
equally cheap, they are indifferent and choose randomly. Finally, to simplify the derivation of the -main results, throughout this article we maintain the assumption that

$$
q v_{\mathrm{H}}>v_{\mathrm{L}} \text {. }
$$

As in the existing models of sales (Varian 1980; Lazear 1986; and Pashigian 1988), the driving force in our model is consumer demand uncertainty and store learning, as opposed to most of the sales models in the marketing literature (e.g., Gallego and van Ryzin 1994), in which inventory control is the driving force and learning plays no role. Our assumption of a homogeneous market allows us to focus on the issues of timing of sales and supply of variety while ignoring quantity choice at the beginning of the season and inventory control during the selling season. A novelty of our model is that store learning speed is affected by the impulse of fashionable consumers, not just by the demand uncertainty in the market as in the existing sales models. The parameter $q$ has the interpretation of the service quality of the stores: a store with more competent sales force or more comfortable shopping environment has a greater probability of selling the designs at the list price. Another novelty is that product variety is taken into account explicitly, which allows us to isolate the effects of demand uncertainty from other factors (e.g., fashion premium) that may also affect the importance of fashion to consumers. Moreover, we explicitly model timing of sales with a simple demand structure of fashionable consumers and discount consumers. The idea of discount market is also crucial for our analysis of competitive timing of sales.

We have made a few simplifying assumptions above, chief among which is symmetry regarding designs and stores: all designs have the same list price even though there is no substitution among them for fashionable consumers and all stores have the same service quality. Symmetry regarding designs is assumed to focus our model on the effects of product variety, while symmetry regarding stores is to highlight the impact of store competition. In Section VII below, we discuss the implications of relaxing these and other assumptions and show how to enrich our model to address other issues related to seasonal sales.

\section{Monopolistic Timing of Sales}

Imagine a single store with $k$ designs at the beginning of the season. The store's pricing problem can be solved by backward induction. To understand the basic intuition, assume for now that $k=1$. Let $w_{n}^{\mathrm{m}}(p)$ be the store's expected profits when there are $n$ periods to go (superscript $\mathrm{m}$ stands for "monopoly") and the estimated fashion market size is $p$. By the assumption of zero salvage value, $w_{0}^{\mathrm{m}}(p)=0$. For 
$n \geq 1$, the store chooses between having a sale (charging $v_{\mathrm{L}}$ ) and holding to the list price (charging $\cdot v_{\mathrm{H}}$ ):

$$
w_{n}^{\mathrm{m}}(p)=\max \left\{v_{\mathrm{L}}, p q v_{\mathrm{H}}+(1-p q) \beta w_{n-1}^{\mathrm{m}}\left(p^{\prime}\right)\right\}
$$

where the updated estimate of the size of the fashion market after unsuccessfully charging the list price is given by

$$
p^{\prime}=\frac{p(1-q)}{1-p q} \text {. }
$$

Since $w_{0}^{\mathrm{m}}(p)=0$, in the last period the store charges $v_{\mathrm{L}}$ (has sales) if and only if its estimated size of the fashion market is smaller than

$$
t_{1}=\frac{v_{\mathrm{L}}}{q v_{\mathrm{H}}} .
$$

In all periods before the last one, the store is indifferent between having sales in this period and having sales in the next period after charging the list price in this period if the size of the fashion market $p$ satisfies

$$
v_{\mathrm{L}}=p q v_{\mathrm{H}}+(1-p q) \beta v_{\mathrm{L}} \text {. }
$$

This implies that the threshold size of the fashion market under which the store is indifferent between having sales in this period and in the next period is

$$
t=\frac{v_{\mathrm{L}}(1-\beta)}{q\left(v_{\mathrm{H}}-\beta v_{\mathrm{L}}\right)} .
$$

If the estimated fashion market size is greater than $t$ with $n \geq 2$ periods to go, then charging $v_{\mathrm{H}}$ in the current period is optimal because, if the design does not sell at $v_{\mathrm{H}}$, the store can always have sales in the next period, that is, $w_{n-1}^{\mathrm{m}}\left(p^{\prime}\right) \geq v_{\mathrm{L}}$. If the estimated fashion market size is smaller than $t$, then it is optimal for the store to have sales right away: since the updated estimate is always smaller than the current estimate of the fashion market size, that is, $p^{\prime}<p$, the best the store can do in the next period after unsuccessfully charging $v_{\mathrm{H}}$ in the current period is to have sales. ${ }^{\text {? }}$

The above analysis can be extended to the case of multiple designs $(k \geq 2)$. This extension is important because it illustrates the effect of product variety on timing of sales; it will also be compared to the competitive model of sales to show the effect of store price competition. The monopoly store orders several designs at the beginning of the season but does not know which one of the designs, if any, will

7. This argument holds for all $n \geq 3$. For $n=2$, the result follows from the fact that $t_{1}<t$, so that $p^{\prime}<p<t<t_{1}$. 
be fashionable. The new consideration in the case of multiple designs is how many designs the monopoly store should choose to put on sale when having sales is optimal. Since all designs are perfect substitutes for discount buyers and since there is no substitution among the designs for fashionable buyers, putting more than one design on sale is optimal only if the per-design sales profit $v_{\mathrm{L}}$ exceeds the per-design expected profit from charging the list price $v_{\mathrm{H}}$. By the assumption $q v_{\mathrm{H}}>v_{\mathrm{L}}$, in the last period it is not optimal to put more than one design on sale, and a fortiori, it is never optimal to have more than one design on sale in any period.

For the following proposition, we define

$$
t_{1}^{\mathrm{m}}=\frac{v_{\mathrm{L}}}{q v_{\mathrm{H}}+v_{\mathrm{L}}(k-1)}
$$

and

$$
t^{\mathrm{m}}=\frac{v_{\mathrm{L}}(1-\beta)}{q v_{\mathrm{H}}+v_{\mathrm{L}}[(1-\beta)(k-1)-q \beta]} .
$$

PRoposition 1. In the last period of the season, sales occur if and only if the estimated per-design size of the fashion market is smaller than $t_{1}^{\mathrm{m}}$. In any period except the last one, sales occur if and only if the store estimates that its fashion market is smaller than $t^{\mathrm{m}}$ per design.

The threshold fashion market size $t_{1}^{\mathrm{m}}$ determining end-of-the-season sales is not the same as the threshold $t^{\mathrm{m}}$ during the season. Indeed, sales occur for different reasons in the two cases. Sales at the end of the season may be interpreted as "clearance sales." The store gets zero salvage value for any unsold design while it captures the whole discount market by putting one design on sale, so sales occur if the expected sales profit from a single design is greater than the expected profit of selling it at the list price. The threshold $t_{1}^{\mathrm{m}}$ does not depend on the discount factor. During the season $(n \geq 2)$, the monopoly store's choice is between putting one design on sale in the current period and having sales in the next period. Since the store can always have sales in the next period if necessary, as opposed to getting zero salvage value in the last period after unsuccessfully charging the list price, the threshold $t^{\mathrm{m}}$ is smaller, and sales are less likely during the season than at the end of the season. Moreover, the threshold $t^{\mathrm{m}}$ during the season depends on the discount factor. Indeed, from the expression of $t^{\mathrm{m}}$, we see that sales do not occur during the season when it does not cost anything to hold the good on the shelf $(\beta=1)$. Since our focus is on learning and demand uncertainty, unless otherwise noted, by sales we mean sales during the season.

Except for the different threshold in the last period, the threshold fashion market size that determines the timing of sales does not depend 
on the number of periods left in the season. The reason for this is already clear in the case of $k=1$. In each period, the monopoly store faces a choice of selling the single design early for sure and selling it at the high list price with some probability. The threshold fashion market size during the season is therefore determined by the indifference condition between having sales in this period and having sales in the next period after charging the list price in the current period. Since the trade-off captured by this indifference condition does not depend on the number of periods left in the season, the threshold $t^{\mathrm{m}}$ is independent of $n$.

According to proposition 1, price behavior during the season is simple. If the store's prior estimate of the total size of its fashion market is greater than $k t^{\mathrm{m}}$, it starts with the list price $v_{\mathrm{H}}$ for all its designs. As the designs continue to stay on the shelf, the store adjusts its estimate downward. If the designs are still unsold when, for the first time, the updated estimate falls below the threshold fashion market size $t^{\mathrm{m}}$, the store randomly selects a design and puts it on sale at the discount price $v_{\mathrm{L}}$. Then either the market closes after purchases by discount consumers, or, if no purchase is made at the sales price, the store learns that consumers are fashionable and keeps the list price for the rest of the season. ${ }^{8}$

Although the choice of design on sale is random, the timing of sales, or the period when sales start, if at all, is deterministic in this monopoly model. Since the threshold fashion market size $t^{\mathrm{m}}$ does not depend on the number of periods left, we can work out the timing of sales by reversing the updating rule, starting from $t^{\mathrm{m}}$ and $t_{1}^{\mathrm{m}}$. Let $b_{1}=t^{\mathrm{m}}$ and define $b_{n}$ recursively for each $n \geq 2$ according to the updating rule:

$$
b_{n-1}=\frac{b_{n}(1-q)}{1-b_{n} q} \text {. }
$$

Similarly, let $\hat{b}_{1}=t_{1}^{\mathrm{m}}$, and define $\hat{b}_{n}$ according to the same updating rule above. If the prior per-design estimate $\pi / k$ exceeds $\hat{b}_{N}$, sales never occur, and the store charges $v_{\mathrm{H}}$ throughout the season. If $b_{N-1}<\pi / k<$ $\hat{b}_{N}$, sales occur, if at all, in the last period of the season. For any $i \leq$ $N-1$, if the prior satisfies $b_{i-1}<\pi / k<b_{i}$, sales occur in the $i$ th period of the season, with probability $(1-\pi)+\pi(1-q)^{i-1}$.

8. Thus, after a single unsuccessful sale of a design, the inference is that consumers are fashionable, and so observed average price goes down once in the season and then up immediately. In a more realistic model one can assume that discount buyers do not purchase the designs with probability one when they are on sale, or there is a possibility that consumers are "window-shoppers" with zero valuation. Then stores do not learn immediately that consumers are fashionable after unsuccessful sales, and average price stays down for more periods. 


\section{Implications of the Monopoly Model}

Store location, bar coding, and business cycles. It can be shown directly from the expression of $t^{\mathrm{m}}$ that the threshold fashion market size is higher for stores with a lower $\beta$. That is, stores that discount future profits heavier tend to have earlier sales in the season. Stores at premium locations have lower $\beta$ because they face a greater cost of selling their designs late owing to higher rent or higher opportunity cost of shelf space, and as a result they tend to have earlier sales. Stores at premium locations are also likely to have more frequent customer visits. This means more opportunities for the stores to learn about the market, which also makes sales appear earlier in the season. ${ }^{9}$ We can show that the threshold fashion market size $t^{\mathrm{m}}$ increases as the discount price $v_{\mathrm{L}}$ increases, or as the list price $v_{\mathrm{H}}$ decreases, because it is more costly to delay sales and less profitable to keep the list price. Recent innovations in product labeling and bar coding have reduced the cost of price adjustments. By increasing the net profits from sales, these innovations have equivalently increased the discount price $v_{\mathrm{L}}$, and, as a result, sales tend to occur earlier in the season. Timing of sales also depends on the business cycles. Sales occur earlier during recessions because both the fashion premium $v_{\mathrm{H}}-v_{\mathrm{L}}$ and the total size of the fashion market $\pi$ are likely to decrease in a recession. If business downturns are anticipated before stores order their designs at the start of the season, then stores will likely respond by ordering designs with smaller fashion premiums, which will further precipitate sales in the season.

Store service quality. Service quality $q$ can have opposite effects on the timing of sales. On the one hand, an increase in the quality of the service makes it more likely for the store to sell the designs to fashionable consumers, which tends to delay the timing of sales by increasing the benefits from waiting. This effect can be seen from the expression $t^{\mathrm{m}}$, which decreases as $q$ increases. On the other hand, with better service, the store also learns faster whether its designs are fashionable (updates faster), which tends to drive early sales. This effect can be seen from the updating rule $p^{\prime}=p(1-q) /(1-p q)$ : for a given estimate of the fashion market size, the updated estimate is smaller if $q$ is greater. The overall effect of changing store service quality depends on the comparison of these two effects. For example, since the updating rule is unaffected by the fashion premium and the discount factor, and since the small fashion premium and small discount factor magnify the

9. The comparison is made between stores at premium and nonpremium locations that share some of the same seasonal goods. This does not exclude the possibility that stores at different locations have different mixes of products. Examples of premium locations include popular shopping malls and tourist sites. Premium locations are not exclusive locations where stores pay a higher rent and have few visits per unit of time because they sell higher-priced goods to higher-income consumers. 
effects of $q$ on $t^{\mathrm{m}}$, for a store that faces a market of small fashion premium or has a premium location with higher rent or higher opportunity cost of shelf space, improved service quality is more likely to lead to later sales in the season.

Increasing importance of fashion. Pashigian (1988) observes that since the 1960s fashion has become more important in clothing markets. Increasing importance of fashion may be represented by increasing fashion premium: as fashion becomes more important to consumers, they are willing to pay a higher premium for a fashionable design. As the fashion premium increases, our model predicts later sales because experimenting with the list price becomes more attractive than switching to the discount price. Thus, our model seems to suggest that, as fashion becomes more important to consumers, sales start later. However, the importance of fashion cannot be gauged solely from the difference in willingness to pay. Increasing importance of fashion implies not only greater demand uncertainty as represented by increased fashion premium but also more product variety. The discussion of the relation between timing of sales and the importance of fashion is incomplete unless we address the effects of increasing supply of varieties. This will be done immediately below for the monopoly case and in the next section for the competitive case.

Product variety. The effects of product variety can be readily examined in our model. Fix the total size of the fashion market and consider what happens to the timing of sales as the fashion market is segmented by a greater number of designs. The threshold fashion market size $t_{n}^{\mathrm{m}}$ decreases with $k$, but $k t_{n}^{\mathrm{m}}$ increases with $k$. Since the updating is unaffected by the increase in the number of designs, sales occur earlier when the monopoly begins with more designs on the shelf. ${ }^{10}$ In the case with one good $(k=1)$, the monopoly store balances the tradeoff between selling early and selling cheap. When there are more designs, the monopoly can use one design as a "trial balloon" - if consumers do not buy the design on sale, then they must have high valuation for the remaining items, and the store will keep the list price for the rest of the season. When the number of designs is greater, the risk of putting a "hot" design on sale is reduced, and therefore the balance between selling early and selling cheap is tilted in favor of selling early. ${ }^{11}$

10. If consumers value variety in the sense that $\pi$. or the high valuation $v_{\mathrm{H}}$ increases with $k$, the effect of competition in driving the early start of sales obtained below will be smaller.

11. Throughout this article we assume costless search by consumers. However, it may be argued that, as product variety increases, it becomes more difficult even for impulse consumers to pick out the one they like, and as a result, $q$ may decrease. If so, the effect of an increase in product variety on timing of sales will be accompanied by additional effects of a decrease in $q$. In the monopoly model, a decrease in $q$ slows down store learning but reduces expected profits from selling to fashion buyers so that the overall effects on 
Thus, a monopoly store can have incentives to order several designs, even if doing so does not increase the fashion premium or the size of the fashion market. The benefits of having more varieties can be calculated by comparing the expected profits with $k+1$ and $k$ designs at the beginning of the season, with the prior estimate of the total fashion market size fixed at $\pi$. Clearly, the benefits are nil if $\pi$ is sufficiently large so that sales never occur even with $k+1$ designs (i.e., $\pi$ exceeds $(k+1) \hat{b}^{N}$ where $\hat{b}^{N}$ is calculated as above, with $k+1$ designs $)$ : from the derivation of proposition 1 , since there are no sales, the expected profit is just

$$
\frac{\pi q v_{\mathrm{H}}\left\{1-[\beta(1-q)]^{N}\right\}}{1-\beta(1-q)},
$$

independent of the number of designs. The difference in the expected profits between $k$ and $k+1$ designs is the largest, the marginal benefits of variety the greatest, when $\pi$ is so small that sales occur in the first period of the season even with $k$ designs (i.e., $\pi$ is smaller than $k t^{\mathrm{m}}$ ). ${ }^{12}$ From the expression of sales profits in the proof of proposition 1 (see the appendix), the benefits to the monopoly store of adding an additional design to existing $k$ designs are at most

$$
\left(\frac{q v_{\mathrm{H}}\left\{1-[\beta(1-q)]^{N}\right\}}{1-\beta(1-q)}-v_{\mathrm{L}}\right) \frac{\pi}{k(k+1)} .
$$

Note that the above expression of marginal benefits of product variety is proportional to $1 /[k(k+1)]$. The intuition is simple. Since the store chooses only one design on sale (and since by assumption increasing the number of designs does not change the total size of the fashion market), having one more design reduces the probability of putting a hot design on sale. If the store chooses the hot design on sale, it gets $v_{\mathrm{L}}$ instead of the revenue from selling it at $v_{\mathrm{H}}$ sometime in the season. The probability of choosing the hot design is $1 / k$, and so the marginal benefit of an additional design is proportional to $1 /[k(k+1)]$.

timing of sales are unclear, but in the competitive model it will likely delay sales and thus counterbalance the direct effect of precipitating sales of the increase in product variety (see the discussion in Sec. VI).

12. From the derivation of proposition 1 , the expected profit at the beginning of the season consists of the expected profits from charging the list price for a few periods and then the expected profits from sales. The first part of the profits does not depend on the number of designs. Since sales occur earlier with $k+1$ designs than with $k$ designs, the difference in the expected profits between $k+1$ and $k$ designs is at most the difference in the sales profits $s_{n}(p)$ between $k+1$ and $k$ designs, where $s_{n}(p)$ is as defined in the proof of proposition 1 , and where $n$ and $p$ are, respectively, the number of periods remaining and the per-design size of fashion market when sales occur with $k+1$ designs. This gives the expression that follows, where $n$ is replaced by $N$ and $p$ is replaced by $\pi /(k+1)$ and $\pi / k$, respectively. 


\section{Competitive Timing of Sales}

Now imagine that two stores, $\mathrm{A}$ and $\mathrm{B}$, each with a design at the beginning of the season, compete for a unit-size market consisting of either fashionable consumers or discount buyers. Fashionable consumers like either store A's design or store B's design. Note that, since there is no substitution between the two designs for fashionable consumers, price competition is limited to the discount market in which the two designs are perfect substitutes. Furthermore, if both stores charge the list price $v_{\mathrm{H}}$ and if consumers do not purchase either design, the updated estimate of each store about its fashion market size is $p(1-q) /(1-2 p q)$. Thus, stores update at the same pace under competition and under monopoly. The results we obtain below regarding earlier sales under competition do not rely on any implicit assumption that learning is faster under competition.

Consider first the equilibrium in the last period. Since the salvage value is zero for both stores, each charging $v_{\mathrm{H}}$ is a pure-strategy Nash equilibrium if

$$
p q v_{\mathrm{H}} \geq(1-p) v_{\mathrm{L}},
$$

where $p<1 / 2$ denotes the common estimate of each store's fashion market size. In this case, two stores are optimistic about their chance at their own fashion market, even though each of them can capture the whole discount market by having sales. If the above condition is not satisfied, there is no pure-strategy Nash equilibrium because the estimated size of the fashion market is too small to justify giving up the discount market completely, but since the two designs are perfect substitutes in the discount market, price competition tends to drive down the sales profits below what each store can get by sticking to the list price. Note that neither store charges any price between $v_{\mathrm{L}}$ and $v_{\mathrm{H}}$ because such pricing reduces the store's profits from its fashion market without attracting discount buyers. Moreover, price competition in the discount market does not reduce the prices and profits to zero because each store can always hold on to its fashion market, which provides a lower bound on its profits and the amount of discount it is willing to give away.

Using the standard techniques (see, e.g., Varian 1980), we can show that in the random-strategy equilibrium when $p q v_{\mathrm{H}}<(1-p) v_{\mathrm{L}}$, there is no probability mass point in the randomization support of each store, except at $v_{\mathrm{H}}$. By symmetry, we can let the common randomization support be $\left[\underline{x}, v_{\mathrm{L}}\right] \cup\left\{v_{\mathrm{H}}\right\}$. The lower bound of the support $\underline{x}$ is determined by the condition that each store is indifferent between charging this price (and capturing the whole discount market) and charging $v_{\mathrm{H}}$ to take the chance at its own fashion market: 


$$
(1-p) \underline{x}=p q v_{\mathrm{H}},
$$

which implies

$$
\underline{x}=\frac{p q v_{\mathrm{H}}}{1-p} .
$$

The probability $F(x)$ that each store charges a price below some $x \in$ $\left[\underline{x}, v_{\mathrm{L}}\right]$ is determined by the condition that the other store is indifferent between the price $x$ and $v_{\mathrm{H}}$,

$$
(1-2 p)[1-F(x)] x+p x=p q v_{\mathrm{H}},
$$

which implies

$$
F(x)=\frac{(1-p) x-p q v_{\mathrm{H}}}{(1-2 p) x} .
$$

Note that $F(x)$ is positive for all $x \in\left[\underline{x}, v_{\mathrm{L}}\right]$. Moreover, the assumption $q v_{\mathrm{H}}>v_{\mathrm{L}}$ implies that $F\left(v_{\mathrm{L}}\right)<1$, which shows that there is a probability mass at $v_{\mathrm{H}}$; that is, the probability of each store having sales is strictly less than one. ${ }^{13}$

The above model of two competing stores can be easily extended to the case of many stores. For expositional convenience, we restrict ourselves to the two-store model in the main text, although the result and the proof are stated for the general case of $k$ stores, each with one design. For the following proposition, we define (superscript $c$ stands for "competitive")

$$
t_{n}^{\mathrm{c}}=\frac{v_{\mathrm{L}}}{q v_{\mathrm{H}}\left\{1-[\beta(1-q)]^{n}\right\} /[1-\beta(1-q)]+v_{\mathrm{L}}(k-1)} .
$$

Proposition 2. Suppose there are $n$ periods left in the season. Then sales occur with positive probability if and only if each store's estimate of its fashion market size is smaller than $t_{n}^{\mathrm{c}}$.

From the derivation of proposition 2, when there are $n$ periods remaining in the season, the expected profit of each store as a function of its estimated fashion market size $p$ is given by

$$
w_{n}^{\mathrm{c}}(p)=\frac{p q v_{\mathrm{H}}\left\{1-[\beta(1-q)]^{n}\right\}}{1-\beta(1-q)} .
$$

13. This is where the assumption $q v_{\mathrm{H}}>v_{\mathrm{L}}$ simplifies the analysis in the competitive model. Without this assumption, the equilibrium in the last period is characterized by random sales prices with upper bound $v_{\mathrm{L}}$, and $v_{\mathrm{H}}$ is not in the randomization support. As a result, the expected profit of a store, as a function of its estimated fashion market size, does not take the form of the discounted sum of expected revenue from the fashion market, and the analysis is correspondingly complicated. 
Thus, under competition, each store's profit is as if it just charges the list price $v_{\mathrm{H}}$ in each period. Obviously, this myopic strategy cannot be part of an equilibrium. However, from an ex ante point of view, competing stores cannot expect to do any better than by following this myopic strategy. Under competition, the stores receive no rent from the discount market. It is completely dissipated in store competition.

The random-strategy equilibrium calls for a few comments. In the monopoly store model of Section III, we have seen that the timing of sales is deterministic, but the selection of design for sales is random because the monopoly store has no clue which design is likely to be fashionable. The random-strategy equilibrium in the competitive model here may be understood in a similar way. Because stores do not know whether they are carrying a fashionable design, only a random pricing strategy can guarantee that they will not lose out in the competition. Random strategies are not uncommon either in practice or in the literature. Existing models of sales distinguish two types of sales: the "temporal" sales of Varian (1980) with random prices, and the "spatial" sales of Salop and Stiglitz (1982) with deterministic prices. Temporal sales can be interpreted as unadvertised sales. ${ }^{14}$ Compared to advertised spatial sales, temporal sales are less vulnerable to consumer arbitrage.

Timing of sales can be derived from proposition 2. If stores' prior estimate $\pi$ of the total size of the fashion market is larger than $2 t_{N}^{\mathrm{c}}$, both stores start the season with the list price $v_{\mathrm{H}}$. As the designs continue to stay on the shelves, stores adjust their estimates downward, and at the same time the threshold fashion market size for the start of sales-randomization increases ( $t_{n}^{\mathrm{c}}$ increases as $n$ decreases). Let $i$ be the first period such that each store's estimate of its fashion market size is smaller than $t_{N-i+1}^{\mathrm{c}}$. If the designs are still unsold at the end of period $i-1$, which occurs with probability $(1-\pi)+\pi(1-q)^{i-1}$, the stores start to have sales in period $i$. From the derivation of proposition 2, the probability that a store has sales, or charges a price below $v_{\mathrm{L}}$, is

$$
F_{n}\left(v_{\mathrm{L}}\right)=\frac{(1-p) v_{\mathrm{L}}-w_{n}^{\mathrm{c}}(p)}{(1-2 p) v_{\mathrm{L}}}
$$

where $n=N-i+1$ is the number of periods remaining at the beginning of period $i$.

Price behavior after sales start in period $i$ can be easily derived from proposition 2. If both stores have sales in period $i$, which occurs with probability $F_{n}^{2}\left(v_{\mathrm{L}}\right)$, consumers buy the designs with probability one, and the season is over. If only one store, say store A, has sales, which

14. A store's advertised sales (promotional sales) may also be interpreted as random sales as long as competing stores cannot respond fast enough to undercut its price. 
occur with probability $2 F_{n}\left(v_{\mathrm{L}}\right)\left[1-F_{n}\left(v_{\mathrm{L}}\right)\right]$, then consumers buy from store $\mathrm{A}$ if they are discount buyers or if they like store A's fashion, and they buy from store B only if they like B's fashion and they are in a buying mood. In either case, the season ends after the purchase. If consumers like store B's fashion but are not in a buying mood, store $\mathrm{B}$ infers that consumers like its design with probability one and will charge $v_{\mathrm{H}}$ for the rest of the season. Finally, if both stores charge $v_{\mathrm{H}}$ in period $i$, which occurs with probability $1-F_{n}^{2}\left(v_{\mathrm{L}}\right)$, the season proceeds to period $i+1$ if consumers are discount buyers or if they like one design but are not in a shopping mood. In period $i+1$, the updated estimate $p^{\prime}$ remains below the threshold fashion market size $t_{N-i}^{\mathrm{c}}$ (because $p^{\prime}<p<t_{N-i+1}^{\mathrm{c}}<t_{N-i}^{\mathrm{c}}$ ), and the above description applies with $i+1$ replacing $i$ and $p^{\prime}$ replacing $p$.

\section{Implications of the Competitive Model}

Within-season price variability. Unlike the monopoly case, in which the sales price is equal to the low valuation, price competition for discount buyers implies that observed sales prices can be quite variable because stores must randomize their sales prices in order not to lose to their competitors. However, as the season approaches the end, expected discounts increase. To see this, note first that, after period $i$ when sales start, stores charge the sales price only if they charged $v_{\mathrm{H}}$ in all previous periods and either consumers are discount buyers or they are fashionable but not in a buying mood. From the derivation of proposition 2 , the lower bound of each store's randomization support $\underline{x}_{n}$ is given by

$$
\underline{x}_{n}=\frac{w_{n}^{\mathrm{c}}(p)}{1-p} .
$$

As the number of periods $n$ remaining decreases and as the store's estimate $p$ of its fashion market size is adjusted down, the bound $\underline{x}_{n}$ decreases. Similarly, once sales randomization starts, with $n$ periods remaining in the season, the probability that each store charges a price lower than $x$ in the randomization support is given by

$$
F_{n}(x)=\frac{(1-p) x-w_{n}^{\mathrm{c}}(p)}{(1-2 p) x} .
$$

Clearly, $F_{n}(x)$ increases as the number of periods remaining decreases and as the stores lower the estimates of their fashion market size ( $p$ decreases). This result is consistent with the observation in Pashigian (1988) that stores having sales earlier in the season give smaller discounts. 
Although expected discounts increase as the season approaches the end, observed average price (across designs) implied by the model may not always decrease over the season. When sales start in period $i$, there is a positive probability $2 F_{n}\left(v_{\mathrm{L}}\right)\left[1-F_{n}\left(v_{\mathrm{L}}\right)\right]$ that only one store, say store A, has sales, and with probability $p(1-q)$ consumers do not buy from store B. In this case, store B infers that consumers like its design and will charge $v_{\mathrm{H}}$ for the rest of the season. Thus, as in the case of the monopoly store, the observed average price may go down and then up instead of going down throughout the whole season, although, under both monopoly and competition, the price for a given design cannot go down and then up. This explains why sometimes stores are observed to have sales in the beginning of the season, which is mentioned by Pashigian (1988) as a puzzle to the standard theory of sales. Our model is more successful in this respect because, unlike the standard sales model, in which estimates of consumer willingness to pay are always adjusted down as the season proceeds, we capture the idea that it can go up after unsuccessful sales by introducing the possibility that consumers are discount buyers.

Service quality and other determinants of timing. We concluded in the monopoly case that increases in the service quality of the store have ambiguous effects on the timing of sales because benefits from experimenting with the list price are greater while learning is faster. The same forces exist under competition as well. However, while the effect of increases in the service quality on the speed of learning does not change when there are competing stores, the benefits from experimenting with the list price decrease as store competition increases. Thus, a competitive market is more likely to exhibit a correlation between earlier sales and better services. As in the case of the monopoly store, other determinants of earlier sales are a small fashion premium, the great opportunity cost of holding the good on the shelf, and the small size of the fashion market. We also concluded in the monopoly case that decreasing cost of adjusting prices drives earlier sales and increases store profits by increasing sales profits from the discount market. In contrast, under competition decreasing cost of adjusting prices drives earlier sales but leaves profits unchanged because stores obtain no profits from the discount market.

Store competition. The main result in this section is that competition drives early sales. A monopoly store starts sales when its estimate of per-design fashion market size falls below the threshold size $t^{\mathrm{m}}$, which does not depend on the number of periods left. With two competing stores, sales start with $n$ periods to go if the stores' estimates of their respective fashion market size falls below $t_{n}^{\mathrm{c}}$. Under the assumption that the prior estimates of the total fashion market size are the same under monopoly and under competition, updating of estimates occurs at the same pace. Therefore, sales start earlier under competition 
with $n$ periods to go if $t_{n}^{\mathrm{c}}>t^{\mathrm{m}} \cdot{ }^{15}$ Recall that $t_{n}^{\mathrm{c}}$ decreases with $n$. We have (in the case of $k=2$ )

$$
\begin{aligned}
t_{\infty}^{\mathrm{c}} & =\lim _{n \rightarrow \infty} t_{n}^{\mathrm{c}} \\
& =\frac{v_{\mathrm{L}}[1-\beta(1-q)]}{q v_{\mathrm{H}}+v_{\mathrm{L}}[1-\beta(1-q)]} .
\end{aligned}
$$

It can be verified with a little algebra that $t_{\infty}^{\mathrm{c}}>t^{\mathrm{m}}$, and therefore $t_{n}^{\mathrm{c}}>$ $t^{\mathrm{m}}$ for all $n$.

The reason that price competition in the discount market drives early sales can be understood as follows. A monopoly store balances the trade-off between taking the chance at the fashion market and capturing the discount market for sure. In the competitive equilibrium, the two stores face the same trade-off. However, while a monopoly store can always have sales in the next period after unsuccessfully charging $v_{\mathrm{H}}$ in the current period, such a second chance is not taken for granted under competition. Instead, each store perceives a first-mover advantage in capturing the discount market. The contrast between the second chance under monopoly and the first-mover advantage under competition can be seen by comparing the numerator in the expression of $t^{\mathrm{m}}$ to that of $t_{n}^{\mathrm{c}}$ : under monopoly, the benefit of having sales in the current period, instead of in the next period, represented by $\nu_{L}(1-\beta)$, is extracting the maximum surplus $v_{\mathrm{L}}$ from discount buyers one period earlier, whereas under competition the benefit of having sales in the current period is $v_{\mathrm{L}}$, which is larger than under monopoly. Therefore, under competition the trade-off is tilted in favor of capturing the discount market, implying that sales are more likely under competition. The paradox, of course, is that in equilibrium the first-mover advantage does not exist because price competition completely dissipates the rent in the discount market.

Price competition intensifies as the number of stores in the market increases. This can be modeled by an increase in the number of stores while maintaining the total size of the fashion market and the assumption that each store has one design. It is straightforward to show that $k t_{n}^{\mathrm{c}}$ increases with $k$. Thus, more competition drives earlier sales. To understand the intuition behind this result, note that, as the number of stores increases with the total size of the fashion market fixed, each store commands an increasingly smaller share. Since the profit from each store's fashion market decreases as its share shrinks, the perceived advantage from being the first to capture the whole discount market becomes greater. Therefore, sales occur earlier during the season as competition intensifies.

15. Note that $t^{\mathrm{c}}{ }_{1}=t^{\mathrm{m}}$; ; i.e., the end-of-the-season threshold is the same under monopoly and under competition. 
Product variety. The competitive model can be used to consider the implication of store competition to product variety. Suppose that there are already $k$ stores in the market, each carrying a design, and consider the incentives of a new entrant. If the entrant carries a design that gets $1 /(k+1)$ share of the fashion market, then from the derivation of proposition 2 , the expected profit to the store at the beginning of the season is

$$
\frac{q v_{\mathrm{H}}\left\{1-[\beta(1-q)]^{N}\right\}}{1-\beta(1-q)} \frac{\pi}{k+1},
$$

where $\pi$ is the prior that consumers are fashionable. The above expression can be thought of as the average benefit of variety under competition, which arises from sharing the fashion market. Note that the maximum discount price $v_{\mathrm{L}}$ does not enter the expression, as the stores do not extract surplus from discount buyers. At the end of Section III, we derived the marginal benefit of variety under monopoly, which arises from the reduction in the risk of putting the fashionable design on sale and therefore depends negatively on $v_{\mathrm{L}}$. Comparing the average benefit under competition to the marginal benefit under monopoly, we find that the average benefit is greater, implying that competitive markets offer more varieties.

If there is free entry into the retailing business, in that any store can order a different design at some cost to compete against the designs carried by existing stores, new varieties will be created until the expected profit from price competition equals the cost of ordering a new design. If the cost of ordering a new design falls, there will be more varieties in the market and, hence, greater store competition. As a result, sales will occur earlier in the season. Thus, as in the monopoly model of Section III, our competitive model also predicts a relation between the number of varieties in the market and timing of sales. Elements of an explanation of the empirical relation between the trend of earlier sales and increasing product variety in seasonal goods markets may lie in both models.

\section{Extensions}

The stylized model presented in previous sections allows us to focus on the main issues of sales timing, product variety, and price competition. However, several features of our results are at odds with commonly observed practices in retail markets for seasonal goods. In this section, we extend our model to address some of these inconsistencies. These extensions are not meant to be comprehensive; rather, they are partly chosen to illustrate how our model can be developed further to address other issues regarding seasonal sales. 
A straightforward extension is to combine the monopoly model of Section III and the competitive model of Section V by allowing competing stores to have multiple designs. Suppose that there are $k$ stores, each with $l$ designs that share the fashion market equally. As in the monopoly model, the assumption $q v_{\mathrm{H}}>v_{\mathrm{L}}$ implies that stores randomly select a single design when it is optimal to have sales. Following the proofs of propositions 1 and 2, we can show that the per-design threshold fashion market size with $n$ periods to go is given by

$$
\frac{v_{\mathrm{L}}}{q v_{\mathrm{H}}\left\{1-[\beta(1-q)]^{n}\right\} /[1-\beta(1-q)]+v_{\mathrm{L}}(k l-1)} .
$$

Thus, the competitive timing of sales depends only on the number of designs that share the fashion market, not directly on the number of competing stores (as long as there is more than one). An implication is that the assumption in Section V that each competing store has just one design is without loss of generality.

In our model, when a store with multiple designs of a product has sales, a single design is chosen randomly because putting more than one design on sale only sacrifices the chance of capturing the fashion premium and because all designs are ex ante identical to the store. However, one sometimes observes stores putting several designs on sale at the same time, and the choice of designs for sales is systematic rather than random. This observation can be accommodated in our model by relaxing the assumption of $q v_{\mathrm{H}}>v_{\mathrm{L}}$. If we maintain that all designs have the same list price and discount price, then under the assumption $q v_{\mathrm{H}}<v_{\mathrm{L}}$, the price behavior and sales timing strategy in the monopoly model are similar as described in proposition 1. In particular, a single item will be chosen when sales occur for the first time, so that greater product variety has the same effect of precipitating sales as in the case of $q v_{\mathrm{H}}>v_{\mathrm{L}}$. However, unlike the case of $q v_{\mathrm{H}}>v_{\mathrm{L}}$, in which the "trial" sales turn out to be unsuccessful and the store infers that it is facing a market of fashion buyers, it will not charge $v_{\mathrm{H}}$ until the end of the season. Instead, at some point it will find it optimal to put all remaining designs on a "clearance" sale. A more realistic assumption is that designs differ in fashion premium so that $q v_{\mathrm{H}}>v_{\mathrm{L}}$ for some designs but $q v_{\mathrm{H}}<v_{\mathrm{L}}$ for the others. Then, a few designs with small premium will be chosen first when sales occur later in the season. ${ }^{16}$ The result that greater prod-

16. This result does not contradict the observation that "conventional" designs are less likely to go on sale. Instead of a small fashion premium, conventional designs are most likely to have salvage values close to the discount price, so stores are unlikely to put them on sale. 
uct varieties precipitate sales in the season should carry through to this case as well.

Often, some stores learn faster than others about the demand for their products because of better service quality, and stores can also differ in their fashion market share. Asymmetry among stores in our model affects both timing and pricing strategies of sales. To illustrate this point, consider the situation in the last period in which one of the two stores, say store $\mathrm{A}$, has an edge over its competitor B in the fashion market, either because its service quality is higher $\left(q^{\mathrm{A}}>q^{\mathrm{B}}\right)$ or because it has a greater share of fashion market $\left(p^{\mathrm{A}}>p^{\mathrm{B}}\right)$. Then sales can be more likely in store $\mathrm{B}$ than in store A. More precisely, suppose that $p^{\mathrm{A}}(1-$ $\left.p^{\mathrm{A}}\right) q^{\mathrm{A}}>p^{\mathrm{B}}\left(1-p^{\mathrm{B}}\right) q^{\mathrm{B}}$. Then, if $p^{\mathrm{A}} q^{\mathrm{A}} v_{\mathrm{H}}>\left(1-p^{\mathrm{B}}\right) v_{\mathrm{L}}$ and $p^{\mathrm{B}} q^{\mathrm{B}} v_{\mathrm{H}} \leq$ $\left(1-p^{\mathrm{A}}\right) v_{\mathrm{L}}$, store A charges the list price $v_{\mathrm{H}}$ and, store $\mathrm{B}$ has sales (charges $\left.v_{\mathrm{L}}\right)$, but the opposite situation cannot occur; if $p^{\mathrm{A}} q^{\mathrm{A}} v_{\mathrm{H}} \geq(1-$ $\left.p^{\mathrm{B}}\right) v_{\mathrm{L}}$ and $p^{\mathrm{B}} q^{\mathrm{B}} v_{\mathrm{H}} \geq\left(1-p^{\mathrm{A}}\right) v_{\mathrm{L}}$, each store charges $v_{\mathrm{H}}$, and sales do not occur in either store. Finally, if $p^{\mathrm{A}} q^{\mathrm{A}} v_{\mathrm{H}}<\left(1-p^{\mathrm{B}}\right) v_{\mathrm{L}}$ and $p^{\mathrm{B}} q^{\mathrm{B}} v_{\mathrm{H}}<$ $\left(1-p^{\mathrm{A}}\right) v_{\mathrm{L}}$, store A's edge in the fashion market is too small to justify giving up the discount market completely, so there is no pure-strategy equilibrium. In the last case, both stores can have sales, but only store A has a positive probability of charging the list price while store $B$ concentrates on the discount market. The precise characterization of the equilibrium and the proof are in the appendix. This analysis can also be extended to during the season. Then, if a store has an edge in the fashion market owing to large market share, its expected timing of sales tends to be later in the season. As in Section III, where we argued that higher service quality has ambiguous effects on the timing of sales, if a store has an edge in the fashion market because of its high service quality, there will be two opposite forces affecting timing of sales: the store has a good chance of selling its designs at the list price, which tends to delay sales, but at the same time it learns faster about the demand, which tends to induce early sales. The overall effect on timing is therefore ambiguous.

In our model, fashion premium does not change for the whole duration of the season. That is, even at the end of season, fashionable consumers are willing to pay the same list price for the design they like. However, in a seasonal goods market with fast fashion turnover, the fashion premium is likely to be declining toward the end of the season. This can be modeled by an exogenous pace of declining list price as the season proceeds. An implication is that, as fashion turnover becomes faster (the list price declines faster), the effective length of the season becomes shorter, and sales start earlier. Such a model with an exogenous pace of a declining list price is also more realistic because store prices before the start of sales follow a gradual decline, as opposed to a one-time drop from the list price to some discount prices in the stylized model of the previous sections. 


\section{Concluding Remarks}

Since the 1970s, sales of seasonal designs such as apparel have started earlier in the season while product variety has increased in these markets. This article discovers two links between these two trends: one through a monopoly store's optimal pricing, and the other through store competition. We consider a simple model in which retail stores start the season without knowing which of the designs they have, if any, will be fashionable. Stores initially charge a fashion premium in hopes of capturing their fashion market, but as the end of the season approaches with designs still on the shelves, they adjust their expectations downward. At some point in the season, it becomes more profitable to have sales to capture the discount market. Having a greater number of designs induces the store to put one of them on sale earlier to test the market. Price competition in the discount market also induces stores to start sales early because they perceive a first-mover advantage in having sales before their competitors and because competition reduces the profits from delaying sales. In a market with free entry, a fall in the cost of product innovation results in more product varieties, greater store competition, and sales earlier in the season.

Pashigian's (1988) work is most closely related to ours. He uses a monopoly model to show that, as fashion becomes more important, there is more within-season price variation. Increasing importance of fashion is modeled by a mean-preserving spread of the distribution of consumer valuation. In Pashigian's model, greater product variety means more uncertainty facing the monopoly store and greater heterogeneity among consumers at the same time. By contrast, in our model the increasing importance of fashion implies more uncertainty facing competing stores only. Although increasing demand for individualism has resulted in greater heterogeneity among consumers, a large fraction of consumers strives to own the design that is "in." A model driven entirely by greater uncertainty and competition such as ours captures the essential herding aspect of the fashion phenomenon.

Our results indicate a close relation among the timing of sales, stores' profits, and equilibrium product variety. This observation has at least two important implications for the retailing industry. First, price competition in the discount market imposes a negative externality on the competing stores and drives early sales. Thus, there is collective incentive for the stores to lobby regulators to impose restrictions on the timing of sales and on the amount of discounts. Second, industry regulators must take into account the effect on product variety of regulation policies restricting the amount of discount or the timing of sales. When consumers value product variety, a binding restriction on the timing of sales, together with policies that ensure free entry in the retail business, may result in an increase in product variety and consumer welfare. 


\section{Appendix}

\section{Proofs}

\section{Proof of Proposition 1}

Proposition 1. In the last period of the season, sales occur if and only if the estimated per-design size of the fashion market is smaller than $t_{1}^{\mathrm{m}}$. In any period except the last one, sales occur if and only if the store estimates that its fashion market is smaller than $t^{\mathrm{m}}$ per design.

Proof. Suppose that there are $n$ periods remaining in the season, with probability $p$ consumers like a given design, and with probability $1-k p$ they are discount buyers. The optimal profit of the monopoly store $w_{n}^{\mathrm{m}}(p)$ satisfies the following equation:

$$
w_{n}^{\mathrm{m}}(p)=\max \left\{k p q v_{\mathrm{H}}+\beta(1-k p q) w_{n-1}\left(p^{\prime}\right), s_{n}(p)\right\},
$$

where $p^{\prime}=p(1-q) /(1-k p q)$ and

$$
\begin{aligned}
s_{n}(p)= & (1-k p+p) v_{\mathrm{L}}+(k-1) p q v_{\mathrm{H}} \\
& +\beta(k-1) p(1-q) q v_{\mathrm{H}} \frac{1-[\beta(1-q)]^{n-1}}{1-\beta(1-q)}
\end{aligned}
$$

is the expected profits from putting one design on sale. The first term in the sales profits $s_{n}(p),(1-k p+p) v_{\mathrm{L}}$, is the expected sales profits in the current periodconsumers buy if either they are discount buyers (with probability $k p$ ) or they like the design on sale (with probability $p$ ). The second term, $(k-1) p q v_{\mathrm{H}}$, gives the expected profits from selling one of $k-1$ designs not on sale (with probability $(k-1) p q)$. The third term gives the profits (discounted by $\beta$ ) after an unsuccessful sale (with probability $(k-1) p(1-q)$ ) when the monopoly store learns that consumers like one of $k-1$ remaining designs for sure and charges $v_{\mathrm{H}}$ for each of the remaining $n-1$ periods. The first part in the max expression above gives the expected profits of sticking to $v_{\mathrm{H}}$ for all designs for one more period. The first term, $k p q v_{\mathrm{H}}$, gives the expected profits of selling one of $k$ designs at the fashion price $v_{\mathrm{H}}$. The second term, $\beta(1-k p q) w_{n-1}\left(p^{\prime}\right)$, gives the optimal discounted profits after unsuccessfully charging $v_{\mathrm{H}}$ for all designs, with an updated estimate $p^{\prime}$ and number of periods $n-1$.

Since the salvage value is zero, we have $w_{0}^{\mathrm{m}}(p)=0$ for all $p$. Suppose $n=1$. The following solution is easily obtained:

$$
w_{0}^{\mathrm{m}}(p)= \begin{cases}k p q v_{\mathrm{H}} & \text { if } p>v_{\mathrm{L}} /\left[q v_{\mathrm{H}}+(k-1) v_{\mathrm{L}}\right] \\ (1-k p+p) v_{\mathrm{L}}+(k-1) p q v_{\mathrm{H}} & \text { otherwise. }\end{cases}
$$

Thus, $t_{1}^{\mathrm{m}}$ is the threshold fashion market size when $n=1$.

For $n \geq 2$, since the updated estimate $p^{\prime}$ of the fashion market size is always smaller than the current estimate $p$ after an unsuccessful sale, the principle of optimality implies that the threshold fashion market size $t_{n}^{\mathrm{m}}$ is determined by the condition that the monopoly store is indifferent between having sales in the current period and having sales in the next period after charging $v_{\mathrm{H}}$ for the current period. That is, the threshold $t_{n}^{\mathrm{m}}$ satisfies 


$$
s_{n}(p)=k p q v_{\mathrm{H}}+(1-k p q) \beta s_{n-1}\left(p^{\prime}\right),
$$

which implies that $t_{n}^{\mathrm{m}}=t^{\mathrm{m}}$, as given in the statement of the proposition. Q.E.D.

\section{Proof of Proposition 2}

Proposition 2. Suppose there are $n$ periods left in the season. Then sales occur with positive probability if and only if each store's estimate of its fashion market size is smaller than $t_{n}^{\mathrm{c}}$.

Proof. The proof is by induction. Suppose that $n=1$. Since consumers have not made the purchase, stores have symmetric estimates of their fashion market size. Let the stores' estimate be $p$. Then, if $p>t_{1}^{\mathrm{c}}$, each store charging $v_{\mathrm{H}}$ is a pure-strategy Nash equilibrium because

$$
p q v_{\mathrm{H}}>v_{\mathrm{L}}(1-k p+p) \text {. }
$$

If $p<t_{1}^{\mathrm{c}}$, there is no pure-strategy Nash equilibrium. Each store randomly selects a price from the support $\left[\underline{x}_{1}, v_{\mathrm{L}}\right] \cup\left\{v_{\mathrm{H}}\right\}$. The lower bound of the support $\underline{x}_{1}$ is determined by the condition that each store is indifferent between charging this price and charging $v_{\mathrm{H}}$, which implies that

$$
\underline{x}_{1}=\frac{p q v_{\mathrm{H}}}{1-(k-1) p} .
$$

The probability $F_{1}(x)$ that each store charges a price below a price $x \in \underline{x}_{1}, v_{\mathrm{L}}$ ] is determined by the condition that each store is indifferent between the price $x$ and $v_{\mathrm{H}}$ :

$$
(1-k p)\left[1-F_{1}(x)\right]^{k-1} x+p x=p q v_{\mathrm{H}} .
$$

Since either it is optimal for each store to charge $v_{\mathrm{H}}$ or each store is indifferent between $v_{\mathrm{H}}$ and a price below $v_{\mathrm{L}}$, the expected profit of each store as a function of its estimated size of fashion market is given by $w_{1}^{\mathrm{c}}(p)=p q v_{\mathrm{H}}$. The proposition holds for $n=1$.

Suppose $n=2$ and each store estimates that its design is fashionable with probability $p$. Against a price of $v_{\mathrm{H}}$ by other stores, charging $v_{\mathrm{H}}$ is optimal if

$$
p q v_{\mathrm{H}}+(1-k p q) \beta w_{1}^{\mathrm{c}}\left(p^{\prime}\right) \geq[1-(k-1) p] v_{\mathrm{L}},
$$

where $p^{\prime}=p(1-q) /(1-k p q)$. Therefore, when $n=2$, charging $v_{\mathrm{H}}$ is optimal against a price of $v_{\mathrm{H}}$ by the other store if

$$
p \geq t_{2}^{\mathrm{c}}=\frac{v_{\mathrm{L}}}{q v_{\mathrm{H}}[1+\beta(1-q)]+v_{\mathrm{L}}(k-1)} .
$$

If $p<t_{2}^{\mathrm{c}}$, each store charging $v_{\mathrm{H}}$ cannot be an equilibrium. As in the case of $n=$ 1 , there is no pure strategy equilibrium, and both stores must randomize with positive probability of charging $v_{\mathrm{H}}$ and having sales. Note that regardless of the prices charged by other stores, charging $v_{\mathrm{H}}$ gives a store the same expected profits of $p q v_{\mathrm{H}}+\beta p(1-q) q v_{\mathrm{H}}$ : we have seen that this is the payoff if all other stores charge $v_{\mathrm{H}}$; if $l$ stores charge discount prices ( $v_{\mathrm{L}}$ or lower), the payoff of charging $v_{\mathrm{H}}$ is $p q v_{\mathrm{H}}+[p(1-q)+(k-l-1) p] \beta w_{1}^{\mathrm{c}}\left(p^{\prime}\right)$, where $p^{\prime}=p(1-q) /[p(1-$ $q)+(k-l-1) p]$, resulting in the same expected payoff. Since either it is 
optimal for a store to charge $v_{\mathrm{H}}$ or the store is indifferent between charging $v_{\mathrm{H}}$ and a discount price from the randomization support, the expected profit as a function of the estimated fashion market size $p$ is

$$
w_{2}^{\mathrm{c}}(p)=p q v_{\mathrm{H}}+p(1-q) \beta q v_{\mathrm{H}} .
$$

The lower bound of the support $\underline{x}_{2}$ is determined by the condition that each store is indifferent between charging this price and charging $v_{\mathrm{H}}$, implying

$$
\underline{x}_{2}=\frac{w_{2}^{\mathrm{c}}(p)}{1-(k-1) p} .
$$

The probability $F_{2}(x)$ that each store charges a price below a price $x \in\left[\underline{x}_{2}, v_{\mathrm{L}}\right]$ is determined by the condition that each store is indifferent between the price $x$ and $v_{\mathrm{H}}$ :

$$
(1-k p)\left[1-F_{2}(x)\right]^{k-1} x+p x=w_{2}^{\mathrm{c}}(p) .
$$

The proposition holds for $n=2$.

The argument is similar for $n=3$ : given the function $w_{2}^{\mathrm{c}}(p)$ and symmetric estimates of fashion market sizes, all stores charge $v_{\mathrm{H}}$ if the estimate $p \geq t_{3}^{\mathrm{c}}$, while they randomize with positive probability of charging $v_{\mathrm{H}}$ and having sales if $p<t_{3}^{\mathrm{c}}$. By induction, for any $n$, the expected profit to each store, as a function of the estimate $p$ of its fashion market size, is

$$
w_{n}^{\mathrm{c}}(p)=\frac{p q v_{\mathrm{H}}\left\{1-[\beta(1-q)]^{n}\right\}}{1-\beta(1-q)},
$$

and the threshold fashion market size $t_{n}^{\mathrm{c}}$ satisfies

$$
w_{n}^{\mathrm{c}}\left(t_{n}^{\mathrm{c}}\right)=\left[1-t_{n}^{\mathrm{c}}(k-1)\right] v_{\mathrm{L}},
$$

which gives the expression for $t_{n}^{\mathrm{c}}$ stated in the proposition. Q.E.D.

\section{The Asymmetric Case}

Proposition A1. Suppose $n=1, p^{\mathrm{A}} q^{\mathrm{A}} v_{\mathrm{H}}<\left(1-p^{\mathrm{B}}\right) v_{\mathrm{L}}$, and $p^{\mathrm{B}} q^{\mathrm{B}} v_{\mathrm{H}}<$ $\left(1-p^{\mathrm{A}}\right) v_{\mathrm{L}}$, but $p^{\mathrm{A}}\left(1-p^{\mathrm{A}}\right) q^{\mathrm{A}}>p^{\mathrm{B}}\left(1-p^{\mathrm{B}}\right) q^{\mathrm{B}}$. Then, in the random-strategy equilibrium, store A's probability of having sales is positive and less than one, while store B has sales with probability one.

Proof. First, we show that store B charges $v_{\mathrm{H}}$ with zero probability. Let $\underline{x}^{\mathrm{A}}$ be the greatest lower bound of prices that store $A$ charges in equilibrium. Store A always has the option of charging $v_{\mathrm{H}}$ and getting profits of $p^{\mathrm{A}} q^{\mathrm{A}} v_{\mathrm{H}}$. By charging $x^{\mathrm{A}}$, store $\mathrm{A}$ can earn profits at most equal to $\left(1-p^{\mathrm{B}}\right) \underline{x}^{\mathrm{A}}$. Therefore, we have $\underline{x}^{\mathrm{A}} \geq$ $p^{\mathrm{A}} q^{\mathrm{A}} v_{\mathrm{H}} /\left(1-p^{\mathrm{B}}\right)$. Now store $\mathrm{B}$ can always undercut store $\mathrm{A}$ by charging a price just below $\underline{x}^{\mathrm{A}}$ and get profits equal to $\left(1-p^{\mathrm{A}}\right) \underline{x}^{\mathrm{A}}$. Since $\underline{x}^{\mathrm{A}} \geq p^{\mathrm{A}} q^{\mathrm{A}} v_{\mathrm{H}} /\left(1-p^{\mathrm{B}}\right)$, store B's profit is at least as great as $\left(1-p^{\mathrm{A}}\right) p^{\mathrm{A}} q^{\mathrm{A}} v_{\mathrm{H}} /\left(1-p^{\mathrm{B}}\right)$. By assumption, this profit is greater than $p^{\mathrm{B}} q^{\mathrm{B}} v_{\mathrm{H}}$, which is what store $\mathrm{B}$ gets by charging $v_{\mathrm{H}}$. Therefore, store B never charges $v_{\mathrm{H}}$.

Next, we show that store A charges $v_{\mathrm{H}}$ with positive probability. Suppose not. Let $\bar{x}^{\mathrm{A}}$ and $\bar{x}^{\mathrm{B}}$ be the smallest upper bound of equilibrium prices of store $\mathrm{A}$ and store $\mathrm{B}$, respectively. We already know $\bar{x}^{\mathrm{A}}, \bar{x}^{\mathrm{B}} \leq v_{\mathrm{L}}$. In equilibrium $\bar{x}^{\mathrm{A}}=\bar{x}^{\mathrm{B}}=$ 
$\bar{x}$, otherwise the store with the greater upper bound of randomization support has no incentives to charge the prices between the two upper bounds. Suppose that there is no mass point at $\bar{x}$ for store B. Since store B never charges $v_{\mathrm{H}}$, by charging $\bar{x}$ store A gets zero share of the discount market. Store A's equilibrium profit is therefore arbitrarily close to $p^{\mathrm{A}} \bar{x}$, which is smaller than $p^{\mathrm{A}} q^{\mathrm{A}} v_{\mathrm{H}}$, contradicting the assumption that store A never charges $v_{\mathrm{H}}$. Thus, store $\mathrm{B}$ assigns a positive probability to $\bar{x}$. Similarly, since by assumption store A never charges $v_{\mathrm{H}}$, and we already know store $\mathrm{B}$ never charges $v_{\mathrm{H}}$, store A must assign a positive probability to $\bar{x}$. But then each store could get greater profits by reassigning the probability mass from $\bar{x}$ to just below it, which is a contradiction.

Next, we show that the upper bound of the price support for store $\mathrm{B}$ is $v_{\mathrm{L}}$. By the above argument, since store A charges $v_{\mathrm{H}}$ with positive probability and store B never charges $v_{\mathrm{H}}$, there is a mass point at $\bar{x}$ in store B's price support, and there is no mass point at $\bar{x}$ in store A's price support. It follows that, by charging $\bar{x}$, store B gets all the discount market when store A chooses $v_{\mathrm{H}}$ and zero share of the market when store A is not charging $v_{\mathrm{H}}$. If $\bar{x}<v_{\mathrm{L}}$, store B could obtain greater profits by reassigning the probability mass at $\bar{x}$ to a price between $\bar{x}$ and $v_{\mathrm{L}}$, which is a contradiction.

Clearly, in equilibrium the lower bound of the price support for the two stores must be equal, otherwise the store with the smaller lower bound of randomization support has no incentives to charge the prices between the two lower bounds. Denote the common lower bound as $\underline{x}$. Since store A is indifferent between charging $\underline{x}$ and $v_{\mathrm{H}}, \underline{x}$ is equal to $p^{\mathrm{A}} q^{\mathrm{A}} v_{\mathrm{H}} /\left(1-p^{\mathrm{B}}\right)$. For store $\mathrm{A}$ to be indifferent between charging $\underline{x}$ and charging any price in the interval $\left[\underline{x}, v_{\mathrm{L}}\right]$, the price distribution $F^{\mathrm{B}}(x)$ function of store B satisfies

$$
\left(1-p^{\mathrm{A}}-p^{\mathrm{B}}\right)\left[1-F^{\mathrm{B}}(x)\right] x+p^{\mathrm{A}} x=p^{\mathrm{A}} q^{\mathrm{A}} v_{\mathrm{H}},
$$

which gives

$$
F^{\mathrm{B}}(x)=\frac{\left(1-p^{\mathrm{B}}\right) x-p^{\mathrm{A}} q^{\mathrm{A}} v_{\mathrm{H}}}{\left(1-p^{\mathrm{A}}-p^{\mathrm{B}}\right) x} .
$$

Similarly, the price distribution function $F^{\mathrm{A}}(x)$ of store A must satisfy

$$
F^{\mathrm{A}}(x)=\frac{\left(1-p^{\mathrm{A}}\right)(x-\underline{x})}{\left(1-p^{\mathrm{A}}-p^{\mathrm{B}}\right) x} .
$$

It can be verified that $F^{\mathrm{A}}\left(v_{\mathrm{L}}\right)<1$, so that store A charges $v_{\mathrm{H}}$ with positive probability, and $F^{\mathrm{B}}\left(v_{\mathrm{L}}\right)<1$, so that store $\mathrm{B}$ puts a probability mass at $v_{\mathrm{L}}$. Q.E.D.

\section{References}

Coase, R. 1972. Durability and monopoly. Journal of Law and Economics 15 (April): 14349.

Feng, Y., and Gallego, G. 1995. Optimal starting times for end-of-season sales and optimal stopping times for promotional fares. Management Science 41 (August): 1371-91.

Fudenberg, D., and Tirole, J. 1983. Sequential bargaining with incomplete information. Review of Economic Studies 50 (April): 221-47.

Gallego, G., and van Ryzin, G. 1994. Optimal dynamic pricing of inventories with stochastic demand over finite horizons. Management Science 40 (August): 999-1020. 
Gul, F. 1987. Noncooperative collusion in durable goods oligopoly. Rand Journal of Economics 18 (Summer): 248-54.

Gul, F.; Sonnenschein, H.; and Wilson, R. 1986. Foundations of dynamic monopoly and the Coase conjecture. Journal of Economic Theory 39 (June): 155-90.

Krider, R., and Weinberg, C. 1998. Competitive dynamics and the introduction of new products: The motion picture timing game. Journal of Marketing Research 35 (February): $1-15$.

Lazear, E. 1986. Retail Pricing and Clearance Sales. American Economic Review 76 (March): 14-32.

Pashigian, B. P. 1988. Demand uncertainty and sales: A study of fashion and markdown pricing. American Economic Review 78 (December): 936-53.

Pashigian, B. P., and Bowen, B. 1991. Why are products sold on sale? Explanations of pricing regularities. Quarterly Journal of Economics 106 (November): 1015-38.

Pashigian, B. P.; Bowen, B.; and Gould, E. 1995. Fashion, styling, and the within-season decline in automobile prices. Journal of Law and Economics 38 (October): 281-309.

Salop, S., and Stiglitz, J. 1982. The theory of sales: A simple model of equilibrium price dispersion with identical agents. American Economic Review 72 (December): 1121-30.

Sobel, J. 1984. The timing of sales. Review of Economic Studies 51 (July): 353-68.

Stokey, N. 1981. Rational expectations and durable goods pricing. Bell Journal of Economics 12 (September): 112-28.

Varian, H. 1980. A model of sales. American Economic Review 70 (September): 651-59. 